\title{
The clinical and genetic distinction between familial supravalvular aortic stenosis (Eisenberg syndrome) and Williams-Beuren syndrome
}

\author{
Joy M. Samanich • Terry L. Levin • Walter E. Berdon
}

Received: 21 June 2012 / Accepted: 28 June 2012 /Published online: 29 July 2012

(C) Springer-Verlag 2012

Sir,

Recently, an article about Williams-Beuren syndrome [1] appeared in Pediatric Radiology. Characteristic facies, intellectual disability, as well as supravalvular aortic stenosis (SVAS) are typical of Williams syndrome (WS) (OMIM \#194050). Familial aortic stenosis, or Eisenberg syndrome [2] (OMIM\#185500), represents a separate group of patients with autosomal-dominant SVAS in which affected members have normal facies and average intelligence. The history of Eisenberg-type familial SVAS and WS, once considered part of a single condition, is an interesting one. Because of the commonality of the cardiac lesion in these two groups, advances in the genetic basis of Eisenbergtype familial SVAS led to the discovery that both WS and familial SVAS result from an abnormality in the elastin gene $(E L N)$. In 1993 Keating [3], a molecular geneticist, used linkage analysis to suggest that ELN, located at 7q11.23, was the candidate gene for SVAS. Later publications identified several families with familial SVAS in whom the ELN gene was disrupted by either a small deletion or translocation.

\section{J. M. Samanich}

Department of Genetics, Montefiore Medical Center,

Bronx, NY, USA

T. L. Levin $(\bowtie)$

Department of Radiology, Montefiore Medical Center,

714 Forest Ave.,

Mamaroneck, NY 10543, USA

e-mail: jebl1@optonline.net

e-mail: tlevin@montefiore.org

W. E. Berdon

Department of Radiology, Columbia Presbyterian Medical Center,

New York, NY, USA
Based on the identification of the genetic abnormality present in familial SVAS, fluorescent in situ hybridization (FISH) analysis of patients with the WS phenotype was performed, and complete deletion of the ELN gene was identified. Haploinsufficiency of additional genes has been implicated in the other abnormalities characteristic of WS.

The history of familial SVAS and its relationship to WS has been largely forgotten. Recent interest in the genetic cause of WS is directly related to the genetic breakthroughs in patients with isolated familial SVAS. Because of the commonality of the cardiac lesion in these two groups, advances in one disease led to discoveries in the second.

\section{References}

1. Berdon WE, Clarkson PM, Teele RL (2011) Williams-Beuren syndrome: historical aspects. Pediatr Radiol 41:262-266

2. Eisenberg R, Young D, Jacobson B et al (1964) Familial supravalvular aortic stenosis. Am J Dis Child 108:341-347

3. Keating MT (1995) Genetic approaches to cardiovascular disease. Circulation 92:142 